\title{
Adolescent Obesity and its association with socio- demographic profile, lifestyle factors, dietary and physical activity patterns; findings from southwestern Nigeria
}

\section{Adeleye Abiodun Adeomi ( $\nabla$ aadeomi@cartafrica.org )}

Obafemi Awolowo University https://orcid.org/0000-0002-6645-7295

Monday Daniel Olodu

Obafemi Awolowo University

Sodiq Yaya

Obafemi Awolowo University

Adediti Ademiju

Obafemi Awolowo University

Raphael Ajibade

Obafemi Awolowo University

\section{Research}

Keywords: Adolescent obesity, Dietary pattern, physical activity pattern, Lifestyle factors, Nigeria

Posted Date: July 9th, 2020

DOI: https://doi.org/10.21203/rs.3.rs-40677/v1

License: (c) (i) This work is licensed under a Creative Commons Attribution 4.0 International License.

Read Full License 


\section{Abstract}

\section{Background}

The prevalence of adolescent obesity is rising in all parts of the world, but only very few studies have considered factors influencing obesity among Nigerian adolescents. This study therefore aimed to determine the prevalence of obesity and its association with socio-demographic profile, lifestyle factors, dietary patterns and physical activity patterns among in-school adolescents in Southwest, Nigeria.

Method

A total sample size of 400 in-school adolescents was selected through a multi-stage sampling technique from secondary schools in lle-Ife. The dietary patterns were assessed using a 92-item QFFQ, while the activity patterns were assessed using the physical activity questionnaire for older children and adolescents. Data were analyzed using IBM SPSS.

Result

There were 211 (52.8\%) males and 189 (47.3\%) females, with mean ages of $14.8 \pm 2.1$ and $14.4 \pm$ 1.9 years respectively. The prevalence of overweight/obesity was $12.8 \%$, and the associated factors were age, sex, class, the number of children in the family, birth orders and the dietary pattern dominated by starchy foods, roots and tubers $(p<0.05)$. However, no significant relationship existed between adolescents' obesity and lifestyle factors, as well as physical activity patterns $(p>0.05)$. After controlling for confounders, age, number of children and birth orders remained significant.

\section{Conclusion}

The prevalence of overweight/obesity was relatively high among the respondents, and this was associated with the age, number of children in the family and the birth order of the adolescents. The findings of this study underscore the importance of family planning to the control of the obesity epidemic in Nigeria.

\section{Background}

Obesity is a public health problem resulting from a long-term imbalance between food intake and energy expenditure.[1, 2] It is a global problem that affects 50 million girls and 74 million boys worldwide. Also, 213 million children and adolescents, and 1.3 billion adults were in the overweight range worldwide.[3] What was once considered a disease of the developed countries, is now a potential health problem in developing countries.[4-6] In 2016, more than 70 percent of overweight/obese people lived in low and middle-income countries.[7, 8] In Sub-Saharan Africa, the prevalence of overweight and obesity increased by almost a third between 1992 and 2005.[6]. Unlike childhood obesity that has plateaued in many highincome countries, [9-11] adolescent obesity has increased substantially around the world [12,13]. The prevalence rates are as high as 15.6 percent for overweight and 4.9 percent for obesity among 
adolescents in the European countries.[14] In Sub-Saharan Africa, the prevalence of 10.6 percent and 2.5 percent for overweight and obesity have been documented.[15]. In Nigeria, the prevalence of overweight and obesity among adolescents ranges from $1.0-8.6$ and $0.0-3.0$ percent respectively.[16, 17]

While genetic factors are estimated to cause more than 40 percent variation in Body Mass Index (BMI), $[18,19]$ environmental factors contribute immensely to obesity epidemic.[20] Studies have showed that socio-demographic variables such as age, sex, education level, wealth and marital status are determinants of obesity [21-25]. Also, unhealthy dietary intake, such as a high intake of refined carbohydrate foods, saturated fats, sugar, and low dietary fibre intake [26-29] have been shown to be associated with increased rates of overweight and obesity. Evidence has also shown that sedentary lifestyles, smoking and alcohol could be risk factors for obesity.[30, 31]

In Nigeria, most studies on obesity focused on women and children. It is important to study obesity in adolescents because of its health implications in them. Obesity in adolescence is associated with several adverse health consequences for the entire life course. It is associated with a higher risk and earlier onset of chronic diseases such as type 2 diabetes, cardiovascular diseases and cancer [30, 32-35]. Also, it has adverse psychosocial consequences and lowers educational attainment [36, 37].

The few studies on adolescent obesity in Nigeria focused mainly on the prevalence, with little or nothing on the determinants.[38-41] More studies are required to elaborate on the influence of different factors on adolescent obesity as this will inform effective prevention and intervention programmes. This study therefore aimed to determine the prevalence of obesity and its association with socio-demographic profile, lifestyle factors, dietary patterns and physical activity patterns among in-school adolescents in Southwest, Nigeria.

\section{Materials And Methods}

\section{Study location and study population}

The study was carried out among in-school adolescents (10 to 19 years old) in lle-Ife, which is a semiurban town in Southwestern part of Nigeria. Adolescents who were acutely ill, had chronic illnesses that could affect their weight (like sickle cell disease anaemia) and those with disabilities that made them unable to stand were excluded from the study.

\section{Sample size and sampling technique}

The sample size was calculated to get an absolute precision of $\pm 5 \%$ using STATCALC on the Epi-Info software. The proportion of expected outcome was taken as $37.2 \%$ which was the proportion of in-school adolescents with obesity from a previous study in Ile-lfe, with an acceptable margin of error of $5 \%$. The calculated sample size was 359 , but was adjusted for an anticipated non-response of $10 \%$, giving a sample size of 400 . Four hundred adolescents were therefore recruited from 6 secondary schools in lle-lfe using multi-stage sampling technique. Two Local Government Areas (LGAs) were selected from the 5 in 
lle-lfe using simple random sampling technique (balloting method) at the first stage. At the second stage, 3 schools each were selected from the list of schools in the selected LGAs. The number of respondents to be selected in each of the schools was determined using proportional allocation. At the third and final stage, the respondents were selected using stratified random sampling technique, with stratification along the line of the different classes.

\section{Research instruments and data collection methods}

A pre-tested structured questionnaire was used for data collection using the assisted self-administered method. The dietary patterns were assessed using 92 -item quantitative food frequency questionnaire (QFFQ), while the activity patterns were assessed using the physical activity questionnaire for older children and adolescents by Kowalski et al[42], which has been validated and used among similar age group in Nigeria.[43] The instruments for anthropometric measurements were be the Seca ${ }^{\circledR}$ electronic bathroom weighing scale (SECA GmbH \& Co, Germany) for measuring weight in 0.1 kilograms $(\mathrm{kg})$. Height was measured to the nearest 0.1 meter using the stadiometer (Leceister ${ }^{\circledR}$ Height Measure, Seca, UK). The anthropometric measurements were done according to standard protocols recommended by the International Society for the Advancement of Kinanthropometry.[44]

\section{Data Management}

Data were analyzed using IBM SPSS version 23. Descriptive analysis of all the variables measured were first done, and the categorical variables were reported as frequencies and proportions/percentages, while the continuous variables were reported as means \pm standard deviation. At bivariate level, crosstabulations were done to test for associations between the different categorical variables (in line with the objective of the study) using the chi-square test. Fisher's exact test was used when there was an expected value was less than 5. T-test for 2 independent samples was used to compare the means of the continuous variables between the 2 categories of the dependent variable (Obese/Not obese). Logistic regression was used to control for confounders and to identify the predictors of obesity out of the independent variables that were significantly associated with obesity at the bivariate level.

Overweight and Obesity were determined using BMI-for-age Z-scores from the WHO reference charts $>+1$ to +2 and obese $>+2$ respectively, and the 2 groups represented obesity in this study.

The responses to the questions on activity patterns were scored, and each of the sections was scored over 5. Afterwards, all the scores from the different sections were scored over 5 . The scores were then categorized into $<2,2.00-3.99$ and $\geq 4$ for low, moderate and high physical activity patterns respectively. [42]

Principal Component Analysis (PCA) was done to reduce the dimension of dietary intake to a small number of dietary patterns. Factors were retained and interpreted for further analysis based on their natural interpretation, visual inflections of the scree-plot of eigen-values construction (Fig. 2) and the percentage of total variance explained. The reliability of the factor analysis was verified using the Kaiser- 
Meyer-Olkin (KMO) test with a sampling adequacy of 0.9 and Bartlett's test of sphericity significant at $p$ $<0.001$.

\section{Ethical considerations}

Ethical clearance was obtained from the Ethical Review Committee, Institute of Public Health, Obafemi Awolowo University, lle-Ife. Permission for the study was obtained from the Local Inspector of Education (L.I.E.) of the selected local government and the Management of the selected schools. Written informed consent was obtained from parents and the adolescents who were 18 years or above, while assent was obtained from respondents younger than 18 years. All information gathered was kept confidential and participants were identified using only serial numbers.

\section{Results}

There were 211 (52.8\%) males and 189 (47.3\%) females, with mean ages of $14.8 \pm 2.1$ and $14.4 \pm$ 1.9 years respectively. Most of them were of the Yoruba ethnicity (92.5\%), were Christians $(73.5 \%)$ by religion and were living with both of the parents (81.5\%). As for the risky lifestyle of the adolescents, 28 $(7.0 \%)$ had smoked before, $7(1,8 \%)$ currently smoked, $66(16.5 \%)$ had taken alcoholic beverages before and $20(5.0 \%)$ were currently taking alcoholic beverages. While majority $(93.0 \%)$ of the respondents did not know, 12 (3.0\%) and 16 (4.0\%) knew that their fathers and mothers had hypertension respectively. Sixteen (4.0\%) and 6 (1.5\%) also reported a history of diabetes in their fathers and mothers respectively.

After the scoring of the responses for the physical activity, the mean score was $21.5 \pm 5.1$, with a range of 10.0 to 39.6 , out of a maximum score of 45 . The respondents were then categorized into low, moderate and high using these scores ie 110 (27.5\%), 289 (72.3\%) and $1(0.3 \%)$ respectively. Using the WHO BMIfor-age references, 51 (12.8\%) of the respondents were overweight or obese. (Fig. 1)

The 92-dietary items on the FFQ were regrouped into 16 dietary groups as seen in Table 2. Three dietary patterns which explained about $52 \%$ of the total variance (total dietary variability) were retained, using PCA. The first component (PCl), which accounted for $35.3 \%$ had the largest positive loadings for fruits, vegetables, meat, poultry, eggs and products, fish and milk. The second component accounted for $9 \%$, and had largest positive loadings for cereals and grain products, starchy fruits, roots and tubers, grain legumes, nuts and seeds. The third component accounted for $7.5 \%$, and had positive loadings for nuts and seeds, fats and oils and condiments and spices. (Table 2). 
Table 1

Relationship between Obesity and Socio-demographic profile of Respondents ( $N=400)$

\begin{tabular}{|c|c|c|c|}
\hline \multirow[t]{2}{*}{ Variables } & \multicolumn{2}{|c|}{ Obesity status (\%) } & \multirow[t]{2}{*}{ Statistics } \\
\hline & Obese $(n=51)$ & Not Obese $(n=349)$ & \\
\hline \multirow[t]{2}{*}{ Age } & $13.6 \pm 1.8$ & $14.8 \pm 2.0$ & $t=4.171$ \\
\hline & & & $P<0.001^{*}$ \\
\hline Sex & $20(9.5)$ & $191(90.5)$ & $\chi^{2}=4.296$ \\
\hline Male & $31(16.4)$ & $158(83.6)$ & $p=0.038^{\star}$ \\
\hline \multicolumn{4}{|l|}{ Female } \\
\hline Religion & $36(12.2)$ & $258(87.8)$ & $\mathrm{LR}=1.179$ \\
\hline Christianity & $15(14.6)$ & $88(85.4)$ & $p=0.554$ \\
\hline Islam & $0(0.0)$ & $3(100.0)$ & \\
\hline \multicolumn{4}{|l|}{ Traditional worshipper } \\
\hline Class & $0(0.0)$ & $22(100.0)$ & $\mathrm{LR}=18.044$ \\
\hline Junior secondary 1 & $9(23.1)$ & $30(76.9)$ & $p=0.003^{*}$ \\
\hline Junior secondary 2 & $11(20.0)$ & $44(80.0)$ & \\
\hline Junior secondary 3 & $18(16.2)$ & $93(83.8)$ & \\
\hline Senior secondary 1 & $13(7.7)$ & $156(92.3)$ & \\
\hline Senior secondary 2 & $0(0.0)$ & $4(100.0)$ & \\
\hline \multicolumn{4}{|l|}{ Senior secondary 3} \\
\hline Number of children in the family & $2(50.0)$ & $2(50.0)$ & $\mathrm{LR}=18.363$ \\
\hline 1 & $0(0.0)$ & $26(100.0)$ & $p=0.001^{\star}$ \\
\hline 2 & 18 (17.6) & $84(82.4)$ & \\
\hline 3 & $21(16.4)$ & 107 (83.6) & \\
\hline 4 & $10(7.1)$ & $130(92.9)$ & \\
\hline$>4$ & & & \\
\hline
\end{tabular}

* Statistically significant; $\chi$ - chi-square test used; LR - Likelihood ratio test used; $t$ - 2 independent samples t-test used; $a$ - professionals eg doctors, lawyers ets; $b$ - Artisans eg tailors, barbers etc; $c$ manual/untrained workers eg cleaners 


\begin{tabular}{|c|c|c|c|}
\hline \multirow[t]{2}{*}{ Variables } & \multicolumn{2}{|c|}{ Obesity status (\%) } & \multirow[t]{2}{*}{ Statistics } \\
\hline & Obese $(n=51)$ & Not Obese $(n=349)$ & \\
\hline Birth order of the child & $12(9.9)$ & $109(90.1)$ & $\mathrm{LR}=14.839$ \\
\hline 1 & $7(6.7)$ & $97(93.3)$ & $p=0.005^{\star}$ \\
\hline 2 & $22(25.0)$ & $66(75.0)$ & \\
\hline 3 & $5(10.4)$ & $43(89.6)$ & \\
\hline 4 & $5(12.8)$ & $34(87.2)$ & \\
\hline \multicolumn{4}{|l|}{$>4$} \\
\hline Fathers' occupation & $4(10.0)$ & $36(90.0)$ & $\mathrm{LR}=2.247$ \\
\hline Unemployed & $33(14.9)$ & $188(85.1)$ & $p=0.523$ \\
\hline askilled worker & $13(10.3)$ & $113(89.7)$ & \\
\hline bSemi-skilled worker & $1(7.7)$ & $12(92.3)$ & \\
\hline \multicolumn{4}{|l|}{ 'Unskilled worker } \\
\hline Fathers' occupation & $0(0.0)$ & $19(100.0)$ & $\mathrm{LR}=6.100$ \\
\hline Unemployed & $22(15.4)$ & $121(84.6)$ & $p=0.107$ \\
\hline askilled worker & $27(12.2)$ & $194(87.8)$ & \\
\hline bSemi-skilled worker & $2(11.8)$ & 15 (88.2) & \\
\hline \multicolumn{4}{|l|}{ 'Unskilled worker } \\
\hline Family setting & $45(13.3)$ & $294(86.7)$ & $x^{2}=0.549$ \\
\hline Monogamous & $6(9.8)$ & $55(90.2)$ & $p=0.594$ \\
\hline \multicolumn{4}{|l|}{ Polygamous } \\
\hline $\begin{array}{l}\text { * Statistically significar } \\
\text { samples t-test used; a } \\
\text { manual/untrained work }\end{array}$ & $\begin{array}{l}\text { est used; LR - } \\
\text { doctors, lawy }\end{array}$ & $\begin{array}{l}\text { hood ratio test used; } \\
\text {; b - Artisans eg tailor }\end{array}$ & $\begin{array}{l}\text { independent } \\
\text { arbers etc; c - }\end{array}$ \\
\hline
\end{tabular}


Table 2

Component Matrix for 3 components representing major dietary patterns among Adolescents in Ile-Ife

\begin{tabular}{|lccc|}
\hline & \multicolumn{3}{c|}{ Components } \\
\cline { 2 - 5 } & PC1 & PC2 & PC3 \\
\hline Cereals and grain products & .051 & .471 & .056 \\
\hline Starchy fruits, roots and tubers & .057 & .449 & .071 \\
\hline Grain legumes and products & .386 & .458 & .298 \\
\hline Nuts and seeds & .049 & .335 & .346 \\
\hline Vegetables & .557 & .191 & .203 \\
\hline Fruits & .595 & .169 & -.274 \\
\hline Sugars and syrups & .247 & -.167 & .085 \\
\hline Meat & .503 & -.047 & -.174 \\
\hline Poultry & .426 & .053 & -.344 \\
\hline Eggs and products & .409 & .066 & -.278 \\
\hline Fish and products & .427 & -.246 & -.178 \\
\hline Milk and related products & .481 & -.179 & -.169 \\
\hline Fats and oils & .041 & -.306 & .512 \\
\hline Condiments and spices & .047 & -.406 & .536 \\
\hline Juice and sugar-sweetened drinks & .247 & -.294 & -.138 \\
\hline Desserts and snacks & .059 & -.391 & .002 \\
\hline
\end{tabular}

The relationship between obesity and socio-demographic profile is as shown on Table 2. Age $(p<0.001)$, sex $(p=0.038)$, class in the school $(p=0.003)$, number of children in the family $(p=0.003)$ and birth order of the child $(p=0.005)$ were the factors that were statistically significant. There was no statistically significant relationship between obesity and physical activity pattern $\left(\chi^{2}=0.107, p=0.743\right)$, and all the lifestyle factors $(p>0.05)$. The second component (PC2) dominated by high carbohydrate/starchy foods and legumes was significantly associated with obesity $(P=0.033)$, while the others were not.

All independent variables that had a statistically significant relationship $(p<0.05)$ with obesity at the bivariate level were entered into a binary logistic model. (Table 3$)$. Age $(p<0.001)$, number of children in the family $(p=0.014)$ and the birth order of the child $(p=0.002)$ were the factors that remained significantly associated with obesity afterwards. 
Table 3

Relationship between Obesity and the Dietary Patterns $(\mathrm{N}-400)$

\begin{tabular}{|llll|}
\hline Variables & Obesity status (\%) & Statistics \\
\cline { 2 - 3 } & Obese $(\mathbf{n = 5 1 )}$ & Not Obese $(\mathbf{n = 3 4 9 )}$ & \\
\hline PC1 & $-0.0942612 \pm 0.95$ & $0.137746 \pm 1.01$ & $t=-0.754$ \\
& & & $P=0.453$ \\
\hline PC2 & $-0.2305216 \pm 0.77$ & $0.336865 \pm 1.03$ & $t=-2.175$ \\
& & & $P=0.033^{*}$ \\
\hline PC3 & $0.0654382 \pm 0.97$ & $-0.0095626 \pm 1.01$ & $t=0.514$ \\
& & & $P=0.609$ \\
\hline * Statistically significant; $t-2$ independent samples $t$-test used \\
\hline
\end{tabular}


Table 4

Predictors of Obesity using Binary Logistic Regression ( $N=400)$

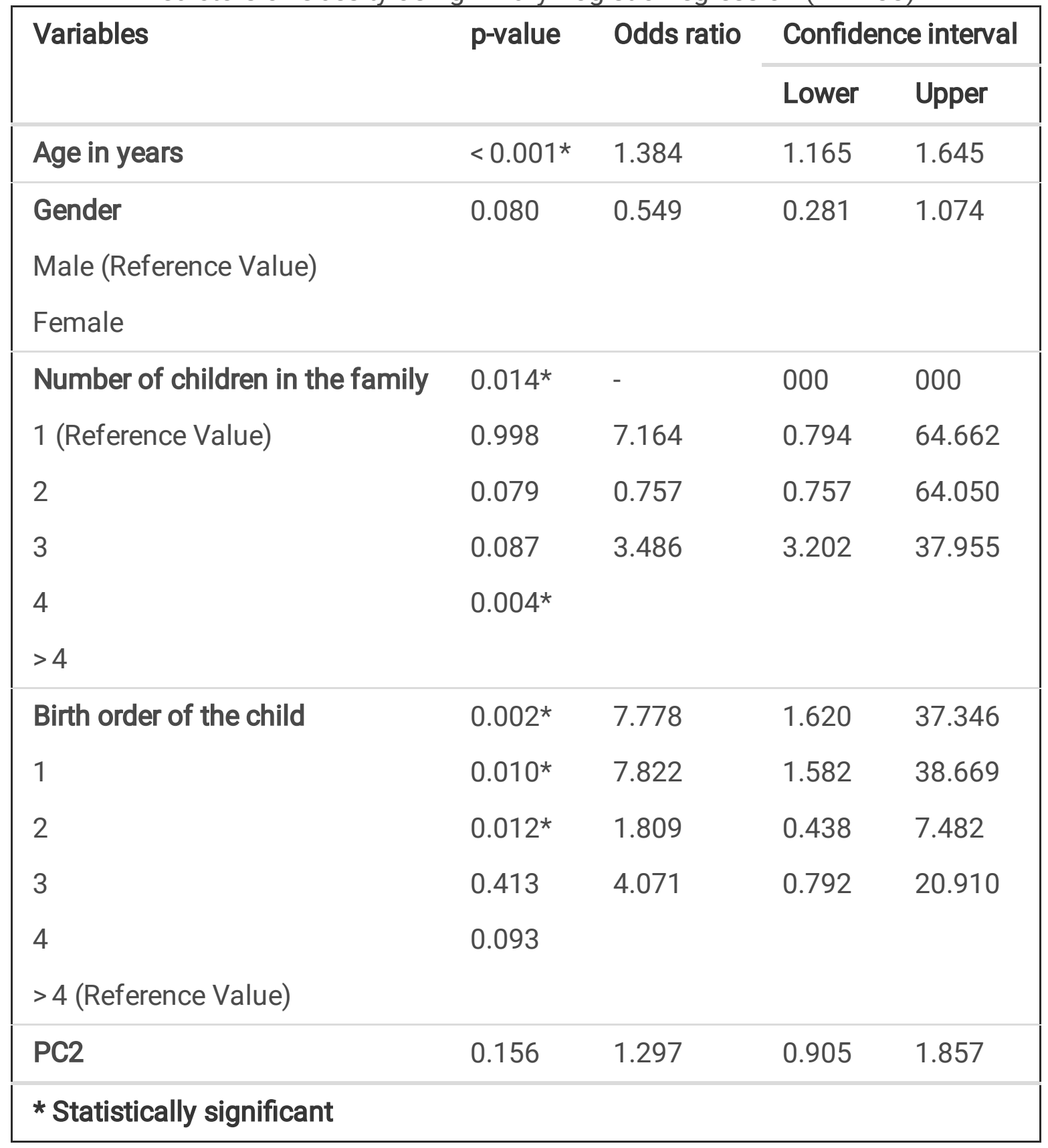

\section{Discussion}

The prevalence of overweight and obesity combined in this study is $12.8 \%$, which is higher than what some authors had previously reported in Southwestern Nigeria.[45-47] Several other recent Nigerian studies have reported similar or even higher rates for overweight/obesity among Nigerian adolescents. $[38,48-52]$ This rising prevalence of obesity among Nigerian adolescents should be a thing of concern to all stakeholders in adolescent health. A quick response to stem this tide therefore becomes necessary to prevent the associated health conditions which can result in lower quality of life in adulthood.

This study showed that the prevalence of obesity was significantly higher in the early adolescence period. This finding corroborates earlier studies that similarly observed higher prevalence rates of overweight and 
obesity in lower adolescent ages.[47] The reason could be as a result of the increase in hormonal secretion which accompanied the growth spurt at this time, and often may be responsible for the excess fat deposition.[53] The present study also found that females were more likely to be obese compared to males. Similar findings have been documented previously in studies done among adolescents.[46, 47] Differences in hormonal secretion, $[53,54]$ lower involvement of females in rigorous physical activities and the cultural preference for girls [55] are some of the possible reasons that have been adduced by different researchers. However, other studies showed a higher prevalence among males compared to females.[13,56] These difference may be due to the age distribution and/or culture of the different study areas.

The dietary component dominated by carbohydrate/ starchy foods and roots and tubers foods were significantly associated with adolescent obesity. Studies have shown that consumption of carbohydrate/ starchy foods are associated with weight gain. $[57,58]$ The high glycemic index of the food may play a vital role in weight gain. Conversely, higher consumption of whole grains, legumes, nuts, fruits and vegetables have been associated with a lower risk of chronic non-communicable diseases and obesity $[59,60]$. There is therefore a need for nutritional education intervention programmes for adolescents, especially within the school systems.

The number of children in the family remained significantly associated with adolescent obesity even after controlling for confounders in the present study. A similar finding showed that a few siblings are a risk factor of overweight/obesity,[61] whereas more numbers lower the risk for overweight.[62] A possible explanation for this finding is that additional siblings might increase cost for food and general upkeep of the children, thereby limiting the average spending on food per child. Another probable explanation is that increased number of children increases the child's play, thereby increasing physical activity which has been shown to be protective. This study also shows that being the first or second child is associated with adolescent obesity, with first and second child being 8 times more likely to be overweight/obese compared to those who birth order is greater than 4 . Studies have reported similar findings with a higher risk of overweight with being the only child. $[62,63]$ These findings underscore the importance of family planning to the control of the obesity epidemic in Nigeria.

Studies have demonstrated that significant relationship exists between physical activity and body weight gain [64-67], suggesting that sedentary lifestyle plays a role in excessive weight gain. However, our result showed that no significant relationship exists between physical activity patterns and body weight gain. This finding was in agreement with similar results reported by other researchers $[68,69]$ who worked among adolescents. The discrepancy in these results may be attributable to the different sample sizes, and the populations studied. It was, however, noted that only one respondent in the present study could be classified as having high physical activity with nearly 3 out of 10 having low physical activity. This pattern of reduced physical activity among adolescents should be discouraged. All the stakeholders including the government, school authorities and parents should put measures in place to discourage sedentary lifestyle and encourage increased physical activity among adolescents. 
This study is not without any limitations. Since the dietary habits of respondents was self-reported, it is prone to social desirability bias or recall bias. This was however minimized by assuring the respondents of absolute confidentiality, and taking only a 30-day recall. The study was descriptive cross-sectional in design, therefore cannot be used to infer cause and effect.

\section{Conclusion}

This study found that the prevalence of overweight/obesity was relatively high among the respondents. Among the socio-demographic factors, age, gender, class, number of children and birth order were significantly associated with obesity. The dietary pattern rich in starchy foods, roots and tubers was also significantly associated with obesity among the adolescents. Obesity had no significant association with physical activity patterns and the lifestyle factors among the respondents. After controlling for confounders, age, number of children in the family and the birth order of the children remained significantly associated with obesity. Effective nutrition education is needed to change dietary habits that are detrimental to adolescents. The school authority should also check the availability of unhealthy foods within the school environment. The findings of this study also underscore the importance of family planning to the control of the obesity epidemic in Nigeria.

\section{Abbreviations}

BMI Body mass index

$\mathrm{Cl}$ Confidence interval

FFQ Food Frequency Questionnaire

KMO Kaiser-Meyer-Olkin

LGA Local Government Area

LIE Local Inspector of Education

OR Odds ratio

PCA Principal Component Analysis

QFFQ Quantitative Food Frequency Questionnaire

SPSS Statistical Package and service solutions

WHO World Health Organization

\section{Declarations}




\section{Declarations}

\section{Ethics approval and consent to participate}

Ethical clearance was obtained from the Ethical Review Committee, Institute of Public Health, Obafemi Awolowo University, lle-lfe. Permission for the study was obtained from the Local Inspector of Education (L.I.E.) of the selected local government and the Management of the selected schools. Written informed consent was obtained from parents and the adolescents who were 18 years or above, while assent was obtained from respondents younger than 18 years. All information gathered was kept confidential and participants were identified using only serial numbers.

\section{Consent for publication}

Not applicable

\section{Availability of data and materials}

The datasets used and/or analyzed during the current study are available from the corresponding author on reasonable request.

\section{Competing interests}

The authors declare that they have no competing interests

\section{Funding}

This research was funded by the authors

\section{Authors' contribution}

AAA conceived and designed the study while MDO, SY, AA, and RA make a substantial contribution in the implementation phase. All authors were involved in data collection, analysis and interpretation. All authors read and approved the final manuscript.

\section{Acknowledgement}

We appreciate all the parents of the participants, and the students for their cooperation throughout the data collection phase. Also, we are grateful to the school management and the Head Teachers for their invaluable contributions and support. 
AAA and MDO were supported by the Consortium for Advanced Research Training in Africa (CARTA). CARTA is jointly led by the African Population and Health Research Center and the University of the Witwatersrand and funded by the Carnegie Corporation of New York (Grant No-B 8606.RO2), Sida (Grant No:54100029), the DELTAS Africa Initiative (Grant No: 107768/Z/15/Z). The DELTAS Africa initiative is an independent funding scheme of the African Academy of Sciences (AAS)'s Alliance for Accelerating Excellence in Science in Africa (AESA) and supported by the New Partnership for Africa's Development Planning and Coordinating Agency (NEPAD Agency) with funding from the Wellcome Trust (UK) and the UK government. The statements made and views expressed are solely the responsibility of the Fellows.

\section{References}

1. Barlow SE. Expert committee recommendations regarding the prevention, assessment, and treatment of child and adolescent overweight and obesity: summary report. Pediatrics. 2007;120 Suppl.

2. Agarwal R, Bills JE, Light RP. Diagnosing obesity by body mass index in chronic kidney disease: An explanation for the "obesity paradox?". Hypertension. 2010;56:893-900.

3. Abarca-Gómez L, Abdeen ZA, Hamid ZA, Abu-Rmeileh NM, Acosta-Cazares B, Acuin C, Adams RJ, Aekplakorn W, Afsana K, Aguilar-Salinas CA, Agyemang C. Worldwide trends in body-mass index, underweight, overweight, and obesity from 1975 to 2016: a pooled analysis of 2416 populationbased measurement studies in 128.9 million children, adolescents, and adults. Lancet. 2017;390:2627-42.

4. Campbell T, Campbell A. Emerging disease burdens and the poor in cities of the developing world. J Urban Heal. 2007;84 SUPPL. 1:54-64.

5. Sodjinou R, Agueh V, Fayomi B, Delisle H. Obesity and cardio-metabolic risk factors in urban adults of Benin: Relationship with socio-economic status, urbanisation, and lifestyle patterns. BMC Public Health. 2008;8:1-13.

6. Ziraba AK, Fotso JC, Ochako R. Overweight and obesity in urban Africa: A problem of the rich or the poor? BMC Public Health. 2009;9:1-9.

7. WHO. Tenfold increase in childhood and adolescent obesity in four decades: new study by Imperial College London and WHO. 2017.

8. Meera Shekar and Barry Popkin.Eds. Obesity : Health and Economic Consequences of an Impending Global Challenge. 2020.

9. Van Jaarsveld CHM, Gulliford MC. Childhood obesity trends from primary care electronic health records in England between 1994 and 2013: Population-based cohort study. Arch Dis Child. 2015;100:214-9.

10. Ogden CL, Carroll MD, Lawman HG, Fryar CD, Kruszon-Moran D, Kit BK, et al. Trends in obesity prevalence among children and adolescents in the United States, 1988-1994 through 2013-2014. JAMA - J Am Med Assoc. 2016;315:2292-9. 
11. Keß A, Spielau U, Beger C, Gausche R, Vogel M, Lipek T, et al. Further stabilization and even decrease in the prevalence rates of overweight and obesity in German children and adolescents from 2005 to 2015: a cross-sectional and trend analysis. Public Health Nutr. 2017;20:3075-83.

12. Hardy LL, Mihrshahi S, Gale J, Drayton BA, Bauman A, Mitchell J. 30-year trends in overweight, obesity and waist-to-height ratio by socioeconomic status in Australian children, 1985 to 2015. Int J Obes. 2017;41:76-82.

13. Zhang J, Wang $\mathrm{H}$, Wang Z, Du W, Su C, Jiang H, et al. Prevalence and stabilizing trends in overweight and obesity among children and adolescents in China, 2011-2015. BMC Public Health. 2018;18:1-7.

14. Olaya B, Moneta MV, Pez O, Bitfoi A, Carta MG, Eke C, et al. Country-level and individual correlates of overweight and obesity among primary school children: A cross-sectional study in seven European countries. BMC Public Health. 2015;15:1-12.

15. Muthuri SK, Francis CE, Wachira LJM, LeBlanc AG, Sampson M, Onywera VO, et al. Evidence of an overweight/obesity transition among school-aged children and youth in Sub-Saharan Africa: A systematic review. PLoS One. 2014;9:e92846-6.

16. Akinpelu AO, Oyewole OO, Oritogun KS. Overweight and Obesity: Does It Occur In Nigerian Adolescents in an Urban Community? Int J Biomed Heal Serv. 2008;4:11-7. http://www.asopah.org.

17. Omisore AG, Omisore B, Abioye-Kuteyi EA, Bello IS, Olowookere SA. In-school adolescents' weight status and blood pressure profile in South-western Nigeria: urban-rural comparison. BMC Obes. 2018;5:2. doi:10.1186/s40608-018-0179-3.

18. Maes HHM, Neale MC, Eaves LJ. Genetic and environmental factors in relative body weight and human adiposity. Behav Genet. 1997;27:325-51.

19. Hjelmborg JVB, Fagnani C, Silventoinen K, McGue M, Korkeila M, Christensen K, et al. Genetic influences on growth traits of BMI: A longitudinal study of adult twins. Obesity. 2008;16:847-52.

20. Cheung WW, Mao P. Recent Advances in Obesity: Genetics and Beyond. ISRN Endocrinol. 2012;2012:1-11.

21. Okoh M. Socio-demographic correlates of overweight and obesity among women of reproductive age in Nigeria. Afr J Reprod Health. 2013;17:66-76.

22. Abrha S, Shiferaw S, Ahmed KY. Overweight and obesity and its socio-demographic correlates among urban Ethiopian women: Evidence from the 2011 EDHS. BMC Public Health. 2016;16:1-7.

23. Ukegbu PO, Uwaegbute AC, Echendu CA, Ejike C, Anyika-Elekeh JU, Asumugha VU, et al. Obesity and associated factors in young adults attending tertiary institutions in south-eastern Nigeria. South African J Clin Nutr. 2017;30:43-8.

24. TH R, IO O MAO. Predictors of Obesity among Adolescents in Ekiti State, Nigeria. Glob J Endocrinol Metab. 2018;2:11-4.

25. Adetunji AE, Adeniran KA, Olomu SC, Odike Al, Ewah-Odiase RO, Omoike IU, et al. Socio-demographic factors associated with overweight and obesity among primary school children in semi-urban areas of mid-western Nigeria. PLoS One. 2019;14:1-12. 
26. Hawkes C. Uneven dietary development: Linking the policies and processes of globalization with the nutrition transition, obesity and diet-related chronic diseases. Global Health. 2006;2:1-18.

27. Onyiriuka AN, Umoru DD, Ibeawuchi AN. Weight status and eating habits of adolescent Nigerian urban secondary school girls. SAJCH South African J Child Heal. 2013;7:108-12.

28. Popkin BM, Adair LiS, Ng SW. NOW AND THEN: The Global Nutrition Transition: The Pandemic of Obesity in Developing Countries. Nutrients. 2017;58:1-10.

29. Adebimpe WO. Prevalence and knowledge of risk factors of childhood obesity among school-going children in Osogbo, south-western Nigeria. Malawi Med J. 2019;31:19-24.

30. Lobstein T, Baur L, Uauy R. Obesity in children and young people: a crisis in public health. Obes Rev. 2004;5(Suppl 1):4-104.

31. Senbanjo IO, Oshikoya KA. Physical activity and body mass index of school children and adolescents in Abeokuta, Southwest Nigeria. World J Pediatr. 2010;6:217-22.

32. Must A, Jacques PF, Dallal GE, Bajema CJ, Dietz WH. Long-term Morbidity and Mortality of Overweight Adolescents: A follow-up of the Harvard Growth Study of 1922 to 1935 . N Engl J Med. 1992;327:1350-5.

33. Abdullah A, Stoelwinder J, Shortreed S, Wolfe R, Stevenson C, Walls $\mathrm{H}$, et al. The duration of obesity and the risk of type 2 diabetes. Public Health Nutr. 2011;14:119-26.

34. Park MH, Falconer C, Viner RM, Kinra S. The impact of childhood obesity on morbidity and mortality in adulthood: A systematic review. Obes Rev. 2012;13:985-1000.

35. WHO. Obesity. 2020.

36. Caird J, Kavanagh J, O'Mara-Eves A, Oliver K, Oliver S, Stansfield C, et al. Does being overweight impede academic attainment? A systematic review. Health Educ J. 2014;73:497-521.

37. Quek YH, Tam WWS, Zhang MWB, Ho RCM. Exploring the association between childhood and adolescent obesity and depression: a meta-analysis. Obes Rev. 2017;18:742-54.

38. Musa DI, Toriola AL, Monyeki MA, Lawal B. Prevalence of childhood and adolescent overweight and obesity in Benue State, Nigeria. Trop Med Int Heal. 2012;17:1369-75.

39. Ene-Obong H, Ibeanu V, Onuoha N, Ejekwu A. Prevalence of overweight, obesity, and thinness among urban school-aged children and adolescents in southern Nigeria. Food Nutr Bull. 2012;33:242-50.

40. Akinlade A. Prevalence of Obesity among Adolescents in Senior Secondary Schools in Oyo State, Nigeria. J Nutr Heal Food Sci. 2014;2.

41. Kelvin AA, Sanusi RA. Nutritional status of in-school adolescents in Ekiti state, Nigeria. Glob J Med Public Heal. 2016;5:1-11.

42. Kowalski KC, Ph D. The Physical Activity Questionnaire for Older Children (PAQ-C) and Adolescents ( PAQ-A ) Manual. Recreation. 2004; August.

43. Odunaiya NA, Ayodele OA, Oguntibeju OO. Physical activity levels of senior secondary school students in Ibadan, western Nigeria. West Indian Med J. 2010;59:529-34. 
44. International Society for the Advancement of Kinanthropometry. International Standards for anthropometric Assessment. 2001;:53-5.

45. Adegoke SA, Olowu WA, Adeodu OO, Elusiyan JB, Dedeke IO. Prevalence of overweight and obesity among children in Ile-ife, south-western Nigeria. West Afr J Med. 2009;28:216-21.

46. Sabageh AO, Ojofeitimi EO. Prevalence of obesity among adolescents in Ile - Ife, Osun state, Nigeria using body mass index and waist hip ratio : A comparative study. 2013;54:153-7.

47. Akinola IJ, Jarrett OO, Oduwole AO, Senbanjo IO, Njokanma OF, Rogol AD. Short Report Prevalence of overweight and obesity among secondary school adolescents in an urban area of Lagos, Nigeria. African J diabetes Med. 2016;24:21-4.

48. Oduwole AA, Ladapo TA, Fajolu IB, Ekure EN, Adeniyi OF. Obesity and elevated blood pressure among adolescents in Lagos, Nigeria: A cross-sectional study. BMC Public Health. 2012;12:1. doi:10.1186/1471-2458-12-616.

49. Otuneye A, Ahmed P, Abdulkarim A, Aluko O, Shatima D. Relationship between dietary habits and nutritional status among adolescents in Abuja municipal area council of Nigeria. Niger $\mathrm{J}$ Paediatr. 2017;44:128-35.

50. Chukwunonso Ejike ECC, Chidi Ugwu E, Lawrence Ezeanyika US. Physical growth and nutritional status of a cohort of semi-urban Nigerian adolescents. Pakistan J Nutr. 2010;9:392-7.

51. Sadoh WE, Sadoh AE, Uduebor JE, Shaibu M, Ogonor E, Enugwuna FC, et al. Comparison of obesity, overweight and elevated blood pressure in children attending public and private primary schools in Benin City, Nigeria. Niger J Clin Pract. 2017;20:839-46.

52. Chinedu SN, Eboji OK, Emiloju OpC. Trends in weight abnormaity of school children and adolesents in Nigeria. J Med Sci. 2012;12:239-43.

53. Burt Solorzano CM, McCartney CR. Obesity and the pubertal transition in girls and boys. Reproduction. 2010;140:399-410.

54. Sadaf Farooqi I. Genetic and hereditary aspects of childhood obesity. Best Pract Res Clin Endocrinol Metab. 2005;19:359-74. 3 SPEC. ISS..

55. Sobal J, Stunkard AJ. Socioeconomic status and obesity: a review of the literature. Psychol Bull. 1989;105:260-75.

56. De Vito E, La Torre G, Langiano E, Berardi D, Ricciardi G. Overweight and obesity among secondary school children in Central Italy. Eur J Epidemiol. 1999;15:649-54.

57. Swinburn B, Caterson I, Seidell J, James W. Diet, nutrition and the prevention of excess weight gain and obesity. Public Health Nutr. 2004;7:123-46.

58. Van Dam RM, Seidell JC. Carbohydrate intake and obesity. Eur J Clin Nutr. 2007;61:75-99.

59. Fogelholm M, Anderssen S, Gunnarsdottir I, Lahti-Koski M. Dietary macronutrients and food consumption as determinants of long-term weight change in adult populations: a systematic literature review. Food Nutr Res. 2012;56:19103. 
60. Wall CR, Stewart AW, Hancox RJ, Murphy R, Braithwaite I, Beasley R, et al. Association between Frequency of Consumption of Fruit, Vegetables, Nuts and Pulses and BMI: Analyses of the International Study of Asthma and Allergies in Childhood (ISAAC). Nutrients. 2018;10:1-11.

61. Mazur A, Klimek K, Telega G, Hejda G, Wdowiak L, Małecka-Tendera E. RISK FACTORS FOR OBESITY DEVELOPMENT IN SCHOOL CHILDREN FROM SOUTH-EASTERN POLAND. Ann Agric Env Med. 2008;15:281-5.

62. Ochiai H, Shirasawa T, Ohtsu T, Nishimura R, Morimoto A, Obuchi R, et al. Number of siblings, birth order, and childhood overweight: A population-based cross-sectional study in Japan. BMC Public Health. 2012;12:1.

63. Chen AY, Escarce JJ. Family structure and childhood obesity, Early Childhood Longitudinal Study Kindergarten Cohort. Prev Chronic Dis. 2010;7.

64. Collins AE, Pakiz B, Rock CL. Factors associated with obesity in Indonesian adolescents. Int J Pediatr Obes. 2008;3:58-64.

65. Mahfouz AA, Abdelmoneim I, Khan MY, Daffalla AA, Diab MM, Al-Gelban KS, et al. Obesity and related behaviors among adolescent school boys in Abha City, Southwestern Saudi Arabia. J Trop Pediatr. 2008;54:120-4.

66. Planinšec J, Matejek Č. Differences in physical activity between non-overweight, overweight and obese children. Coll Antropol. 2004;28:747-54.

67. Ani Peace Nwanneka E-OHN and UPO. Eating Habits. Activity Pattern and Socioeconomic Factors That Affect the Prevalence of Overweight and Obesity among Adolescents in Urban Areas of Enugu State, Nigeria. Pakistan J Nutr. 2016;15:288-94.

68. Al-Nakeeb Y, Duncan MJ, Lyons M, Woodfield L. Body fatness and physical activity levels of young children. Ann Hum Biol. 2007;34:1-12.

69. Caspersen CJ, Pereira MA, Curran KM. Changes in physical activity patterns in the United States, by sex and cross-sectional age. Med Sci Sports Exerc. 2000;32:1601-9.

\section{Figures}




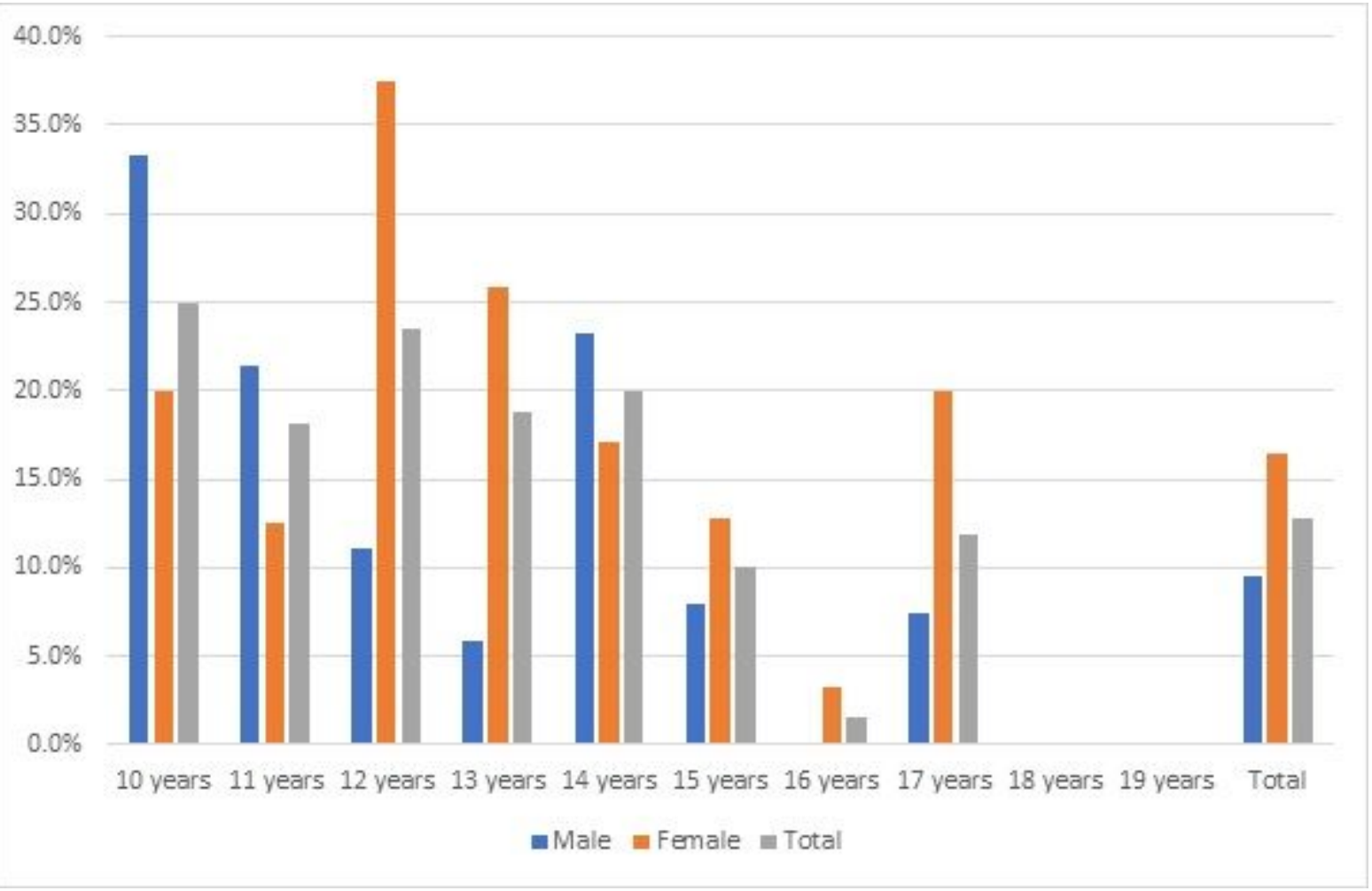

Figure 1

Distribution of the Prevalence of obesity among the respondents according to age and sex.

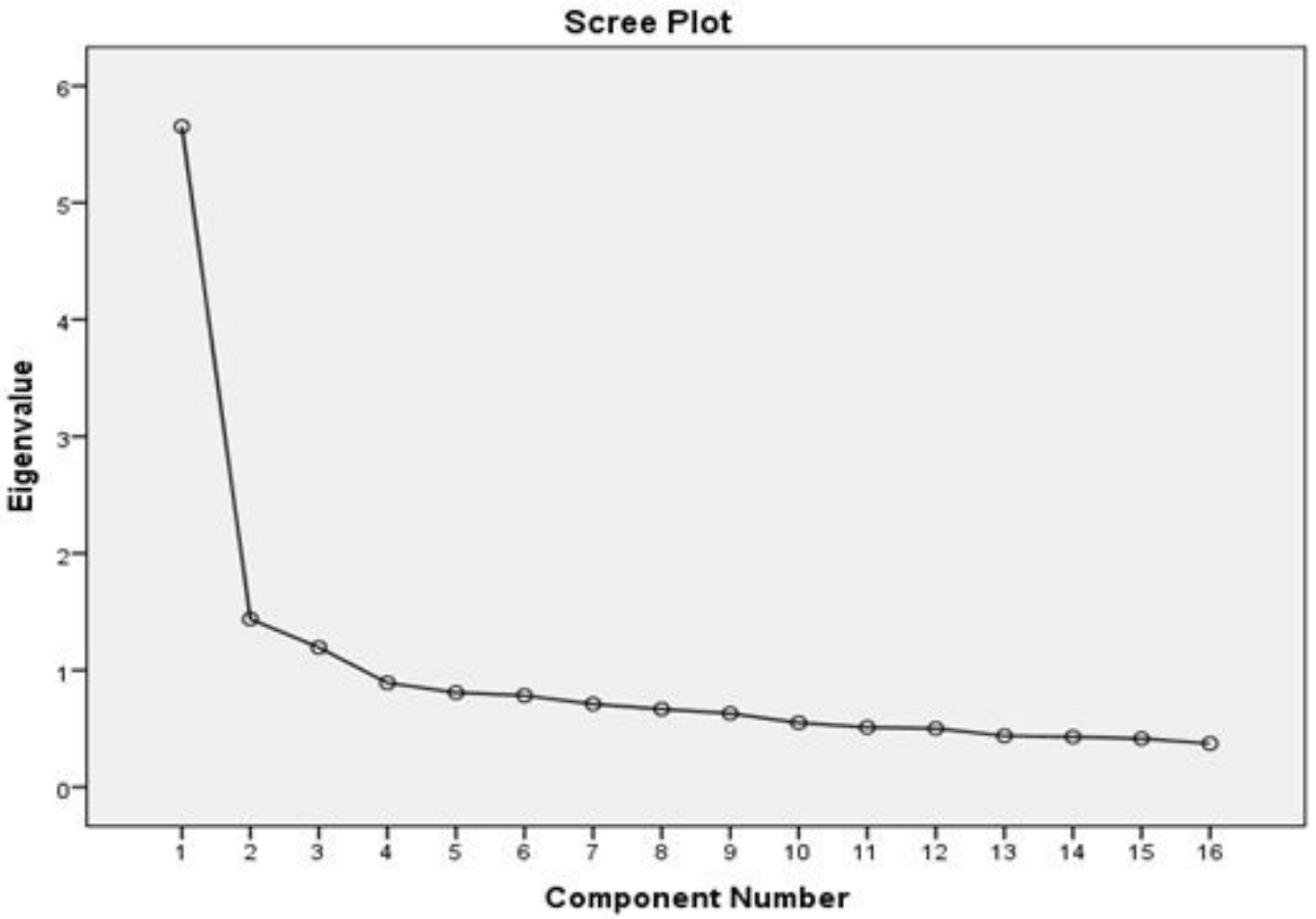

Figure 2

Scree plot of eigen-values after Principal Component Analysis 